\title{
VectorDisk: A Microfluidic Platform Integrating Diagnostic Markers for Evidence-Based Mosquito Control
}

\author{
Sebastian Hin ${ }^{1, \dagger}$, Desirée Baumgartner ${ }^{1,2,+}$, Mara Specht ${ }^{1, \dagger}{ }^{\dagger}$ Jan Lüddecke ${ }^{1}$, \\ Ehsan Mahmodi Arjmand ${ }^{1}$, Benita Johannsen ${ }^{1}$, Larissa Schiedel ${ }^{1}$, Markus Rombach ${ }^{1}$, \\ Nils Paust ${ }^{1,2}$, Felix von Stetten ${ }^{1,2}$, Roland Zengerle ${ }^{1,2}$, Nadja Wipf ${ }^{3,4}{ }^{\mathbb{D}}$, Pie Müller ${ }^{3,4}{ }^{\mathbb{D}}$, \\ Konstantinos Mavridis ${ }^{5}\left(\mathbb{D}\right.$, John Vontas ${ }^{5,6}$ and Konstantinos Mitsakakis ${ }^{1,2, *}$ \\ 1 Hahn-Schickard, Georges-Koehler-Allee 103, 79110 Freiburg, Germany; sebastian.hin@iuvas.de (S.H.); \\ Desiree.Baumgartner@imtek.uni-freiburg.de (D.B.); Mara.Specht@Hahn-Schickard.de (M.S.); \\ Jan.Lueddecke@Hahn-Schickard.de (J.L.); Ehsan.Arjmand@Hahn-Schickard.de (E.M.A.); \\ Benita.Johannsen@Hahn-Schickard.de (B.J.); Larissa.Schiedel@imtek.uni-freiburg.de (L.S.); \\ Markus.Rombach@Hahn-Schickard.de (M.R.); Nils.Paust@Hahn-Schickard.de (N.P.); \\ Felix.von.Stetten@Hahn-Schickard.de (F.v.S.); Roland.Zengerle@Hahn-Schickard.de (R.Z.) \\ 2 Laboratory for MEMS Applications, IMTEK-Department of Microsystems Engineering, \\ University of Freiburg, Georges-Koehler-Allee 103, 79110 Freiburg, Germany \\ 3 Swiss Tropical and Public Health Institute, Socinstrasse 57, 4002 Basel, Switzerland; \\ nadja.wipf@swisstph.ch (N.W.); pie.mueller@swisstph.ch (P.M.) \\ 4 Department of Epidemiology and Public Health, University of Basel, Petersplatz 1, 4001 Basel, Switzerland \\ 5 Foundation for Research and Technology-Hellas, Institute of Molecular Biology and Biotechnology, \\ 70013 Heraklion, Greece; mavridiskos@gmail.com (K.M.); vontas@imbb.forth.gr (J.V.) \\ 6 Pesticide Science Laboratory, Department of Crop Science, Agricultural University of Athens, \\ 11855 Athens, Greece \\ * Correspondence: konstantinos.mitsakakis@imtek.uni-freiburg.de or \\ Konstantinos.Mitsakakis@Hahn-Schickard.de; Tel.: +49-761-203-73252 \\ + These authors have equally contributed.
}

Received: 24 November 2020; Accepted: 15 December 2020; Published: 18 December 2020

\begin{abstract}
Effective mosquito monitoring relies on the accurate identification and characterization of the target population. Since this process requires specialist knowledge and equipment that is not widely available, automated field-deployable systems are highly desirable. We present a centrifugal microfluidic cartridge, the VectorDisk, which integrates TaqMan PCR assays in two feasibility studies, aiming to assess multiplexing capability, specificity, and reproducibility in detecting disk-integrated vector-related assays. In the first study, pools of 10 mosquitoes were used as samples. We tested 18 disks with 27 DNA and RNA assays each, using a combination of multiple microfluidic chambers and detection wavelengths (geometric and color multiplexing) to identify mosquito and malaria parasite species as well as insecticide resistance mechanisms. In the second study, purified nucleic acids served as samples to test arboviral and malaria infective mosquito assays. Nine disks were tested with 14 assays each. No false positive results were detected on any of the disks. The coefficient of variation in reproducibility tests was $<10 \%$. The modular nature of the platform, the easy adaptation of the primer/probe panels, the cold chain independence, the rapid (2-3 h) analysis, and the assay multiplexing capacity are key features, rendering the VectorDisk a potential candidate for automated vector analysis.
\end{abstract}

Keywords: microfluidics; LabDisk; vector-borne diseases; malaria; arboviruses; insecticide resistances; mosquito monitoring 


\section{Introduction}

Vector-borne diseases make up more than $17 \%$ of all infectious diseases globally, and are responsible for more than 700,000 deaths annually, according to the World Health Organization (WHO) [1]. Vectors are arthropod species (e.g., mosquitoes, ticks, and sandflies) that have the capability of acquiring and transmitting at least one type of vector-borne diseases, for example malaria (parasitic disease), dengue, chikungunya, West Nile, Zika, and yellow fever (viral diseases). Malaria is the most prevalent of all, with an estimated 220 million global cases resulting in more than 400,000 deaths annually, while dengue is the most prevalent viral infection, with an estimated 96 million global cases resulting in more than 40,000 deaths annually [1]. Such diseases often appear as epidemic outbreaks, thereby disrupting the countries' healthcare and socioeconomic systems [2].

Although mosquito-borne diseases have typically been a problem in tropical countries, nowadays they also represent a threat in regions with more temperate climates [3,4]. Indicative examples are: (i) the spread of the invasive Asian tiger mosquito (Aedes albopictus), which has been associated with disease transmission in north-western USA [5] and in Europe (in the latter, specifically, it has been associated with several local dengue [6], chikungunya [7,8], and Zika virus [9] outbreaks); and (ii) the continuous circulation of West Nile virus, vectored by the common mosquito Culex pipiens (almost unnoticed until recently), which has caused epidemics with fatalities in several European countries [10-12].

Vector control relying primarily on the use of insecticides has successfully reduced disease cases globally. Since 2000, malaria has been reduced by almost $50 \%$ due to insecticide-treated nets (ITN) and indoor residual spraying (IRS) in combination with case management with artemisinin-based drugs [13]. However, the successes are being challenged by (i) increasing insecticide resistance $[10,14,15]$, and (ii) current tools being ineffective by targeting the wrong vectors. For example, ITN and IRS do not target outdoor biting malaria vectors. Therefore, reliable information on the target vector is crucial, and suitable, integrated, and automated vector analysis tools are desirable to make evidence-based vector control more effective [16].

Three levels of information are crucial for vector surveillance and control: (i) mosquito species identity is essential for differentiating vector from non-vector species (e.g., out of 476 Anopheles species, only 70 are capable of transmitting malaria) [17]; (ii) pathogen detection in the case of malaria vectors, the determination of the Plasmodium species (P. falciparum, P. vivax, P. ovale, or P. malariae), whether the parasites are present in their infective stage [18,19], and-in the case of vectors of viral diseases - the determination of arbovirus species (e.g., West Nile virus, dengue virus); and (iii) the potential involvement of an insecticide resistance mechanism, including target site mutations (DNA) and expression levels of metabolic detoxification genes (RNA) $[20,21]$. Despite various methods that have been developed in the past to address one or more of these characteristics [22], there is no universal tool to collect all necessary information at once; the individual protocols can be very tedious and can involve manual steps such as the dissection of salivary glands [23], or require the analytical skills to perform microscopic identification through morphological examination.

A recent collaborative effort by the authors has resulted in the development and optimization of multiplex TaqMan probe-based reverse transcription polymerase chain reaction (RT-PCR) assays to acquire information on the aforementioned three levels [24]. The current work is a follow-up intended to integrate these TaqMan assays into a microfluidic platform, enabling their automated realization. The integration is achieved on a centrifugal microfluidic cartridge, the VectorDisk, which is an application-specific version of the LabDisk platform. The LabDisk has been shown to operate with pathogen detection from human samples [25-27], but this was typically in a single- or two-target configuration (one or two pathogens simultaneously present in a sample in the form of co-infections). The current work aims to demonstrate the capabilities of the platform in: (i) simultaneously acquiring results from multiple DNA and RNA assays using geometric and color multiplexing (namely multiple microfluidic reaction chambers and detection wavelengths, respectively); (ii) using diluted crude lysates of pools of 10 whole mosquitoes as starting material without the need for exhaustive nucleic 
acid purification; and (iii) easy adaptation from Anopheles- to Aedes-species-specific assay detection. We assessed the feasibility and reproducibility of the assay integration onto the disk in two small-scale studies: the Vector Study, starting from laboratory-reared mosquitoes, to test the malaria assays; and the Nucleic Acid (NA) Study, starting from purified nucleic acids, to test the arbovirus assays [28]. This proof-of-principle work indicates the potential of the platform to be used for fully automated analysis in the framework of integrated vector control.

\section{Materials and Methods}

\subsection{Mosquito Assays}

In order to demonstrate the capability of the VectorDisk platform to simultaneously collect different molecular information for species identification and insecticide resistance, the assays used in this work were designed to detect: (i) DNA-based mosquito species of the Anopheles gambiae species complex; (ii) if present, the DNA of the malaria parasite, thereby differentiating between P. falciparum (the most lethal for humans) and P. ovale/vivax/malariae [18], and the infective stage through the RNA detection of sporozoite-specific P. falciparum transcripts [29]; (iii) knockdown resistance (kdr) point mutations conferring resistance in the target site of the para voltage-gated sodium channel responsible for the insensitivity to dichlorodiphenyltrichloroethane (DDT) and pyrethroids [30-32], as well as target site resistance to organophosphates and carbamates due to insensitive acetylcholinesterase (iAChe) [33]; (iv) overexpression of detoxification loci at the mRNA level [34], which can pinpoint associations with insecticide resistance, such as the cytochrome P450 monooxygenases CYP6P3, CYP6M2, CYP6P4, and CYP6Z1, and the glutathione-S transferase GSTE2 in An. gambiae; (v) the viral RNA, which may be present in arbovirus vectors (i.e., West Nile virus [35] and Zika virus [36]).

\subsection{Vector Study: Manual Preparation of Mosquito Samples (Lysis and Homogenization)}

The insectary at the Swiss Tropical and Public Health Institute provided specimens of the Kisumu colony that originates from an MRA-762 egg batch provided by BEI Resources. For this Vector Study, 50 mosquitoes (Kisumu, 25 male $(\mathrm{m})+25$ female (f)) were used, and the following preparatory steps were performed prior to the automated VectorDisk protocol. The mosquitoes were split into five pools of ten mosquitos each ( 5 males +5 females). It was shown by Mavridis et al. [31] that the use of pools of ten mosquitoes saves time, reduces costs, and allows for more efficient resistance allele screening than in the case of individual mosquito testing. The mosquitoes were preserved in RNAlater (Thermo Fisher Scientific, Waltham, MA, USA), and thawed on a lint-free towel. They were then washed with ultra-pure $\mathrm{H}_{2} \mathrm{O}$ to remove the RNAlater. Subsequently, they were ground manually in a $150 \mu \mathrm{L}$ lysis buffer (RLT Buffer, QIAGEN, Hilden, Germany) with a pestle (on ice). The homogenate was incubated for $10 \mathrm{~min}$ at room temperature. After centrifugation for $2 \mathrm{~min}$ at 16,000 rcf, the supernatant was collected and stored at $-20^{\circ} \mathrm{C}$ in aliquots. Prior to any next experimental step, the lysate was diluted 1:200 with ultra-pure $\mathrm{H}_{2} \mathrm{O}$. In order to acquire results that would allow some reproducibility assessment, one lysate from each pool was diluted and aliquoted for testing three to four times. Thus, we could perform inter-pool as well as intra-pool reproducibility assessments. A summary is shown in Figure 1. A total of 18 disks were used in the Vector Study.

\subsection{Nucleic Acid Study}

The study includes the following purified genomic RNA that was obtained through BEI Resources, NIAID, and NIH: genomic RNA from West Nile virus (WNV), Bird 114, NR-9573, genomic RNA from Zika virus (ZIKV), FLR-Zika virus, NR-50241. The RNA concentration was $<1.0 \mathrm{ng} / \mu \mathrm{L}$. For testing the Plasmodium and the infected stage assays (sample coded as 'PF-INF'), we included in the NA Study a mixture of DNA and RNA extracted from laboratory-reared P. falciparum infected mosquitoes as previously described [29] and their concentration was $120 \mathrm{ng} / \mu \mathrm{L}$. In order to acquire results that would allow some reproducibility assessment, each sample was tested three times in the VectorDisk. 
As each VectorDisk included each primer/probe set twice, we acquired six data points for each assay. A summary is shown in Figure 2. A total of nine disks were used in the NA Study.

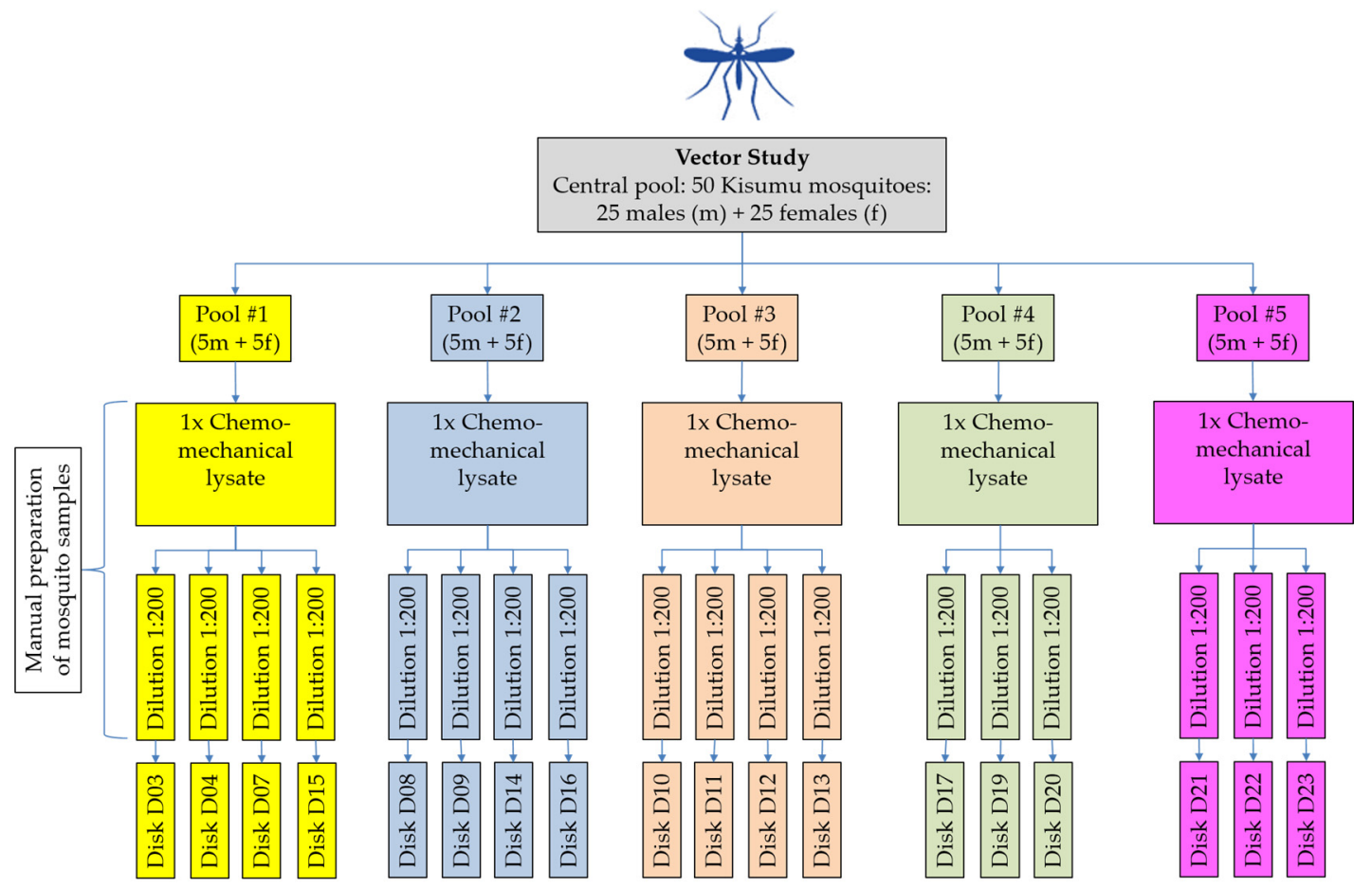

Figure 1. Schematic workflow for manual preparation of mosquito samples prior to VectorDisk tests during the Vector Study.

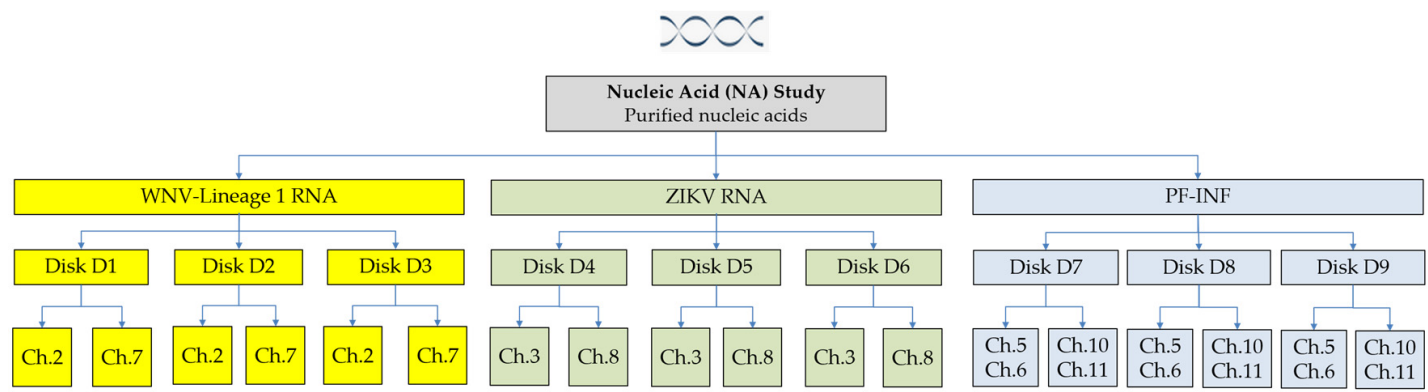

Figure 2. Schematic workflow of testing the three nucleic acid (NA) samples in the VectorDisk during the NA Study. 'PF-INF' represents the mixture of P. falciparum DNA + P. falciparum infective stage RNA.

\subsection{VectorDisk Fabrication}

The microfluidic design was created using SolidWorks2017 (Dassault Systèmes SolidWorks Corp., Waltham, MA, USA). Production of the VectorDisk cartridge was done by Hahn-Schickard Lab-on-a-Chip Foundry [37] using rapid tooling and a scalable and low cost micro-thermoforming process for replication of prototypes [38,39] made of Cyclic Olefin Copolymer foil (COC 6013/8007, $200 \mu \mathrm{m}$ thick, TOPAS Advanced Polymers GmbH, Frankfurt, Germany). For this, an in-house milled (EVO, Kern Microtechnik GmbH, Eschenlohe, Germany) metal master was used on a batch production thermoforming machine (Rohrer AG, Möhlin, Switzerland). No further surface treatment was performed after thermoforming. The primers/probes, together with trehalose as stabilizer (final concentration $50 \mathrm{mM}$ ), were pipetted in the reaction chambers, and the cartridges were then left to dry in an oven at $50^{\circ} \mathrm{C}$ for $1 \mathrm{~h}$. The combinations of the TaqMan probe assays are shown in Tables 1 and 2. Details on the primer/probe design and validation of the assays, including sensitivity results, 
are available in previous studies for the malaria-specific $[29,31]$ and arboviral-specific $[35,36,40]$ assays. The primer/probe sequences are given in Supplementary Tables S1 and S2. The structured foil was sealed with a $200 \mu \mathrm{m}$ thick COC foil (COC 6013/8007, TOPAS Advanced Polymers GmbH, Germany) using an adaptive thermo-sealing process [41] on a modified hot embossing machine (Wickert GmbH, Landau in der Pfalz, Germany). The sealing foil had an opening at the radius that corresponded to the mixing chamber location, where the lyopellet was inserted manually after the thermal sealing. The lyopellets were developed and supplied specifically for these triplex assays (Fast Track Diagnostics, Luxembourg), and their functionality was tested and validated prior to their use in this work [34]. At the end, a piece of pressure-sensitive adhesive foil 9795R (3M, Maplewood, MN, USA) was used to seal the lyopellet mixing chamber. The cartridges were stored with a desiccant in a sealed aluminium pouch to protect reagents from humidity and light until use.

Table 1. VectorDisk assay panel for the Vector Study (triplex or duplex, depending on the assay of the VectorDisk). Targets are detected in 11 different reaction chambers and in three different detection channels (FAM-green, HEX-yellow, and ATTO 647N-red), detecting the fluorescence signal from the corresponding fluorophores in brackets.

\begin{tabular}{cccccc}
\hline $\begin{array}{c}\text { Reaction } \\
\text { Chamber }\end{array}$ & $\begin{array}{c}\text { Assay } \\
\text { Panel }\end{array}$ & $\begin{array}{c}\text { Nucleic Acid } \\
\text { Type }\end{array}$ & $\begin{array}{c}\text { Assay Target } \\
\text { (FAM) }\end{array}$ & $\begin{array}{c}\text { Assay Target } \\
\text { (HEX) }\end{array}$ & $\begin{array}{c}\text { Assay Target } \\
\text { (ATTO 647N) }\end{array}$ \\
\hline 2 & Species ID & DNA & $\mathrm{Aq}^{1}$ & $\mathrm{Ag}^{1}$ & $\mathrm{Aa}^{1}$ \\
3 & Molecular Forms & DNA & $\mathrm{S}^{2}$ & $\mathrm{M}^{2}$ & - \\
4 & Kdr & DNA & $\mathrm{Rw}^{3}$ & ${\mathrm{~S}-w t^{4}}^{3}$ & $\mathrm{Re}^{3}$ \\
5 & Kdr+ & DNA & $\mathrm{R}$ & $\mathrm{S}-\mathrm{wt}$ & - \\
6 & iAChe & DNA & $\mathrm{R}$ & S-wt & - \\
7 & Plasmodium species & DNA & P. falciparum & P. ovm & - \\
8 & Infective stage & RNA & - & PLP1 & - \\
9 & Detox (A) & RNA & RPS7 & CYP6P3 & CYP6M2 \\
10 & Detox (B) & RNA & RPS7 & CYP9K1 & CYP6P4 \\
11 & Detox (C) & RNA & RPS7 & CYP6Z1 & GSTE2 \\
12 & Detox (D) & RNA & RPS7 & CYP6P1 & CYP4G16 \\
\hline
\end{tabular}

${ }_{1}^{1}$ Aq: Anopheles quadriannulatus/merus/melas/bwambae, Ag: An. gambiae s.s. (sensu stricto)/An. coluzzii, Aa: An. arabiensis, ${ }^{2} \mathrm{~S}:$ An. gambiae s.s. (former molecular S-form), M: An. coluzzii (former molecular M-form), ${ }^{3} \mathrm{Rw}$ : Resistant allele west, Re: Resistant allele east, ${ }^{4}$ S-wt: Susceptible (wild type), ${ }^{5}$ P. ovm: P. ovale/vivax/malariae, i.e., the primer set detects all three. The symbol ' - ' means that there were no assay targets expected to be detected in the particular reaction chambers and detection channels.

Table 2. VectorDisk assay panel for the NA Study. Targets are detected in 10 different reaction chambers and in three different detection channels (FAM-green, HEX-yellow, and ATTO 647N-red), detecting the fluorescence signal from the corresponding fluorophores in brackets.

\begin{tabular}{cccccc}
\hline $\begin{array}{c}\text { Reaction } \\
\text { Chamber }\end{array}$ & $\begin{array}{c}\text { Assay } \\
\text { Panel }\end{array}$ & $\begin{array}{c}\text { Nucleic Acid } \\
\text { Type }\end{array}$ & $\begin{array}{c}\text { Assay Target } \\
\text { (FAM) }\end{array}$ & $\begin{array}{c}\text { Assay Target } \\
\text { (HEX) }\end{array}$ & $\begin{array}{c}\text { Assay Target } \\
\text { (ATTO 647N) }\end{array}$ \\
\hline 2 & West Nile virus & RNA & WNV-Lineage 1 & WNV-Lineage 2 & - \\
3 & Zika virus & RNA & - & - & ZIKV \\
4 & Dengue virus & RNA & DENV T1-4 & - & - \\
5 & Plasmodium species ID & DNA & P. falciparum & P. ovm ${ }^{1}$ & - \\
6 & Plasmodium infective stage & RNA & - & - & Pf infective stage \\
7 & West Nile virus & RNA & WNV-Lineage 1 & WNV-Lineage 2 & - \\
8 & Zika virus & RNA & - & - & ZIKV \\
9 & Dengue virus & RNA & DENV T1-4 & - & - \\
10 & Plasmodium species ID & DNA & P. falciparum & P. ovm ${ }^{1}$ & - \\
11 & Plasmodium infective stage & RNA & - & - & Pf infective stage \\
\hline
\end{tabular}

${ }^{1}$ P. ovm: P. ovale/vivax/malariae, i.e., the primer set detects all three. The symbol '-' means that there were no assay targets expected to be detected in the particular reaction chambers and detection channels.

\subsection{VectorDisk Workflow}

For the Vector Study, upon thawing, the mosquito lysate was diluted 1:200 with ultra-pure $\mathrm{H}_{2} \mathrm{O}$ (RNase/DNase-free). Then, $180 \mu \mathrm{L}$ of the diluted lysate was inserted into the VectorDisk inlet 
(Figure 3A). In the automated process in the LabDisk, $160 \mu \mathrm{L}$ of diluted lysate was transferred radially inwards (B) to the mixing chamber with the lyopellet (C), using temperature change-rate (TCR) valving [42] and centrifugo-dynamic inward pumping [43]. A dedicated microfluidic protocol was used in chamber (C) for the rigorous and homogeneous rehydration and mixing of the lyopellet, employing temperature change-rate actuated bubble-mixing [44,45]. The mixture was then transferred to the metering fingers (D), and a volume of $10 \mu \mathrm{L}$ per finger was aliquoted using centrifugo-pneumatic aliquoting [46]. The valving and mixing operations were supported by a dedicated chamber for generating air pressure $(\mathrm{E})$. Then the RT-PCR took place in the reaction chambers $(\mathrm{F})$ where the primers/probes had been dry-stored. The protocol was: $44^{\circ} \mathrm{C}$ for $10 \mathrm{~min}$ (reverse transcription), $97^{\circ} \mathrm{C}$ for $2 \mathrm{~min}$ (initial denaturation for the PCR), and 40 cycles of $97^{\circ} \mathrm{C}$ for $5 \mathrm{~s}$ and $60^{\circ} \mathrm{C}$ for $4 \mathrm{~s}$. The structure (F) serves to generate air pressure for valving and mixing operations. The structure $(G)$ serves as a stiffening structure in order to prevent bending of the foil disk.
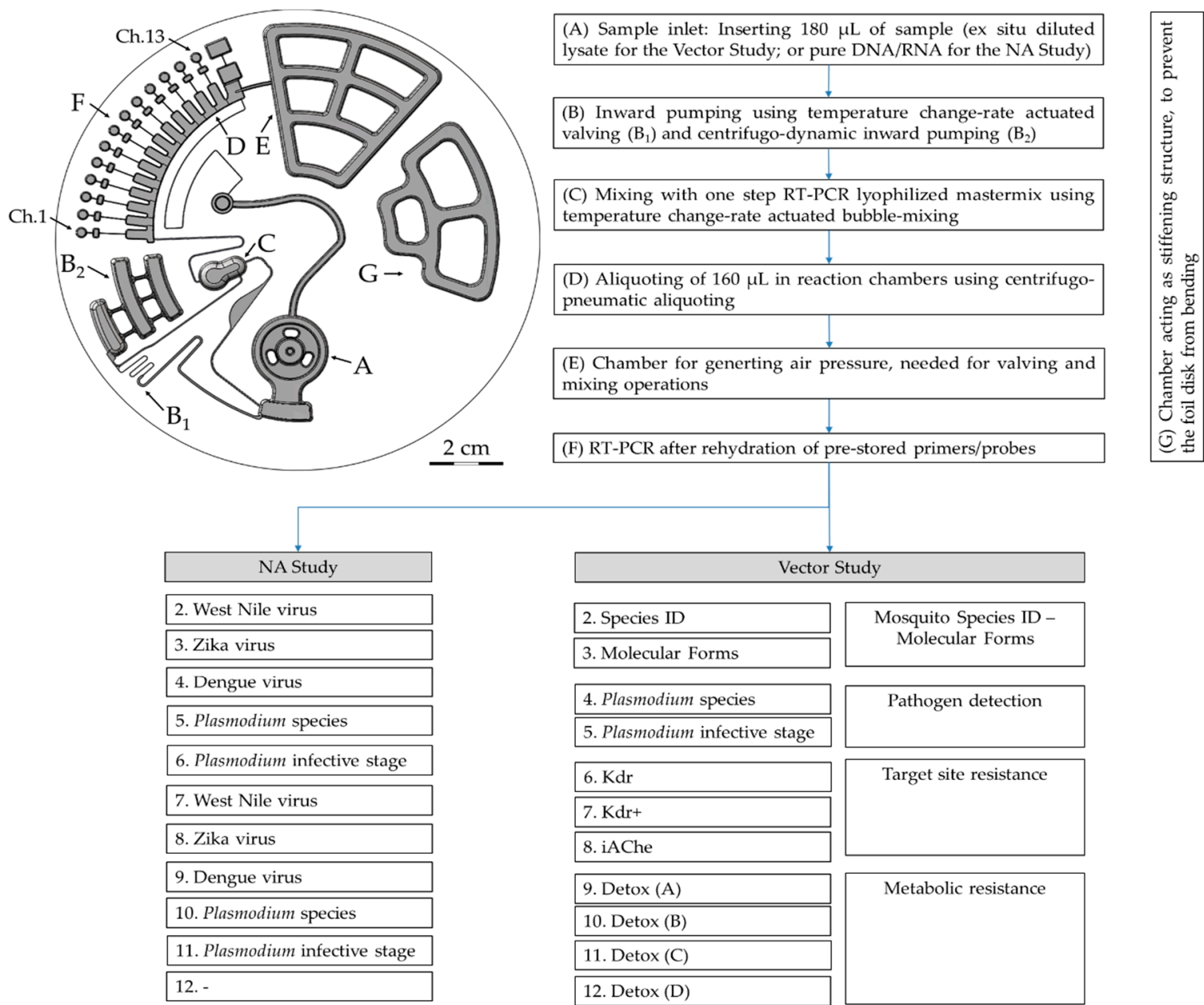

Figure 3. The VectorDisk design where the main unit operations are indicated (A-F). The structure $G$ has the role of stiffening in order to prevent the foil disk from bending. The design was the same for both the Vector- and the NA-Studies. What differed was the type of inserted sample, and the assay panel. 'Ch.1, 2,..' ' refers to the VectorDisk reaction chambers.

For the NA Study, a mixture of $162 \mu \mathrm{L}$ ultra-pure $\mathrm{H}_{2} \mathrm{O}$ and $18 \mu \mathrm{L}$ of purified NA sample was inserted into the inlet. Then, the same fluidic protocol was used as for the Vector Study. At the end, the PCR protocol was started: $50^{\circ} \mathrm{C}$ for $15 \mathrm{~min}$ (reverse transcription), $95^{\circ} \mathrm{C}$ for $3 \mathrm{~min}$ (initial denaturation for the PCR), and 40 or 45 cycles of $95^{\circ} \mathrm{C}$ for $3 \mathrm{~s}$ and $60^{\circ} \mathrm{C}$ for $30 \mathrm{~s}$.

For both studies, the thermocycling protocol and the microfluidic processing were accomplished by means of a dedicated compact LabDisk Player instrument (Figure 4, QIAGEN Lake Constance, Stockach, 
Germany). The detailed microfluidic protocol is described in Supplementary Table S3. Rotational frequency control and air-heating enabled centrifugo-pneumatic [43,46] and thermo-pneumatic microfluidic unit operations [42,44,47], and allowed for a time of 140-180 min from sample inlet to final result (depending on the Vector or NA Study). PCR raw data acquired with the LabDisk Player were converted and analyzed using the RotorGene Software (QIAGEN, Hilden, Germany).

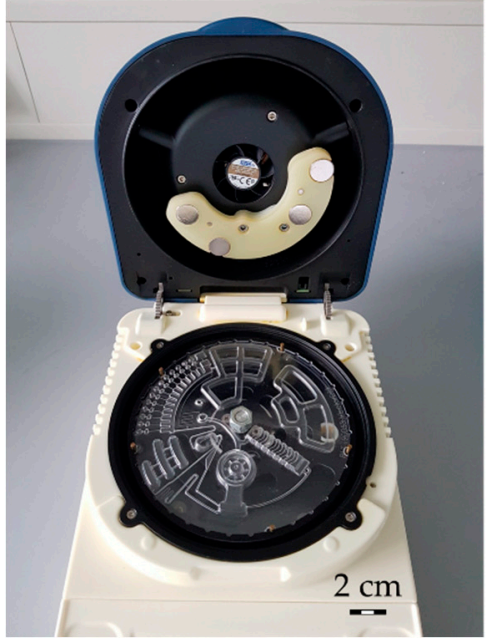

(a)

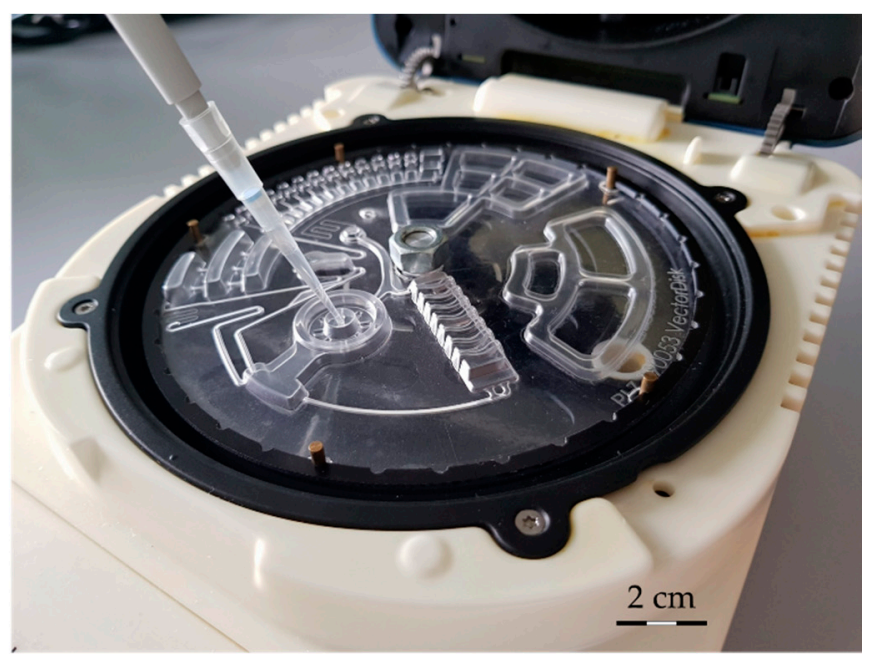

(b)

Figure 4. (a) The LabDisk Player instrument used in the two studies. (b) Pipetting the sample (diluted lysate or purified nucleic acid (NA)) into the VectorDisk.

\section{Results and Discussion}

\subsection{The Vector Study Results}

In the Vector Study, we aimed to demonstrate the simultaneous detection of several DNA and RNA targets in triplex configuration. We tested 18 disks using diluted mosquito lysates as samples, and the arrangement of the assays (primers/probes per reaction chamber) is shown in Table 2.

This work focuses on the semi-quantitative screening of pooled specimens. The usefulness of the initial semi-quantitative screening of pooled mosquito specimens (detection/no detection of a mutation or pathogen) is supported by the two following paradigms. It is not uncommon to screen large numbers of individual mosquitoes and eventually find out that the whole population is wild type for a particular mutation ( $0 \%$ mutant allele frequency) or fixed for another one $(100 \%$ mutant allele frequency). Furthermore, there are instances where the pathogen (Plasmodium or arbovirus) may not be present at all (low transmission settings) in several study sites, and these can be ruled out from a further, more detailed investigation.

The main goal of a semi-quantitative screening is to distinguish clearly between positive and negative results. This can be achieved by considering the gap between the maximum number of PCR cycles and the highest observed $C t$ value of a positive result. A maximum number of 40 or 45 PCR cycles (depending on the study) was fixed, according to authors' previous work taken as reference [34]. All targets which were not detected until that cycle number were considered as negative test results. The highest $\mathrm{Ct}$ values of positive results were in the range of 33 (Supplementary Table S4). The difference between that number and the maximum number of PCR cycles means that the concentration between the 'weakest' positive and the negative is at least two orders of magnitude. Therefore, we can clearly discriminate between positive and negative values. The RPS7 assay, targeting a house-keeping gene, can be considered as a positive amplification control, as it is expected to be positive in one of the three fluorescent wavelengths (FAM) and in four reaction chambers. To compare this with the assays validated in the preceding assay development work, the authors Mavridis et al. [34] had also used 
40 cycles for their PCR (using a ViiA 7 Real-Time PCR System, Applied Biosystems, Waltham, MA, USA), and their highest $\mathrm{Ct}$ value of positive results was of the order of 34 .

In Table 3 we present an overview of the true positive (TP), false negative (FN), true negative (TN), and false positive (FP) rates for each assay and for each mosquito pool, as well as in total for the Vector Study. The classification was done according to the expected outcomes based on previous work with these laboratory mosquitoes [29,31,34]. Some of the included assays were expected to be negative for the specific laboratory-reared mosquitoes (TN, also included in Table 3). In case a positive-expected assay was not detected, it was attributed to be false negative (FN). No FN results were found for the DNA assays. Notably, we also did not observe FP results in the Vector Study for any assay or in any of the five pools (Table 3), which demonstrates the high specificity of the disk-integrated assays. Some representative real-time PCR curves acquired by a VectorDisk are shown in Figure 5.

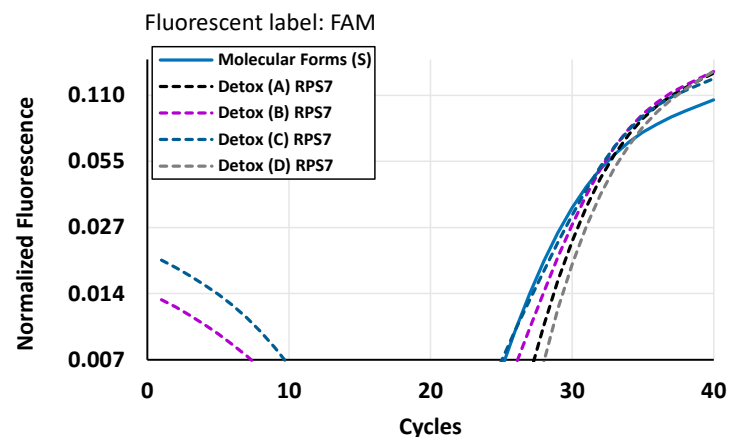

(a)

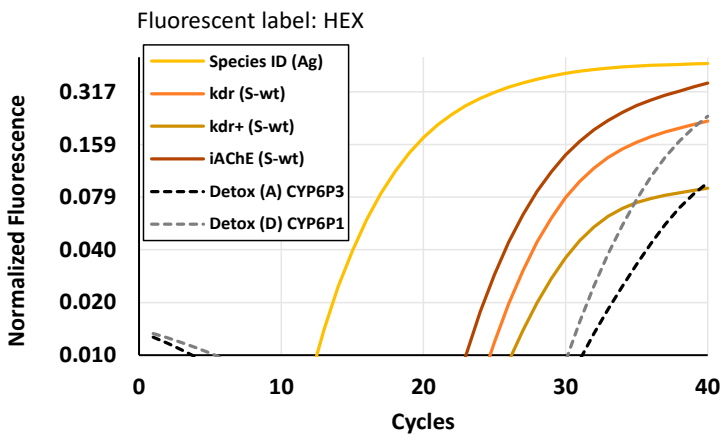

(b)

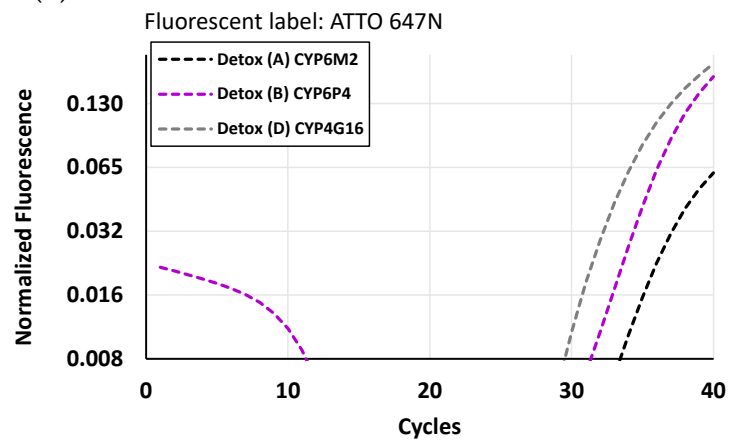

(c)

Figure 5. Indicative LabDisk real-time RT-PCR data acquired for the semi-quantitative analysis of mosquito samples in VectorDisk \#D11, as one representative out of the 18 disks, from all three channels green (a), yellow (b), and red (c). DNA and RNA assays are shown in solid and dashed lines, respectively. The threshold was set to be the $x$-axis itself.

Another key output of this study was the detection of twelve RNA assays using a combination of geometric multiplexing (four reaction chambers: 9, 10,11,12) and color multiplexing (three wavelengths detecting in each chamber). Data from the assay development (previous work of the co-authors Mavridis et al. [34]) indicate that the triplex versus singleplex RT-PCR does not lead to loss of efficiency. The assays were successfully validated in terms of expression levels against standard two-step singleplex PCR assays and microarrays, using laboratory strains and field-caught samples. Further quantitative characterization of the efficiency, sensitivity, specificity, and reproducibility of the assays themselves is available in the co-authors' previous work [34]. In short, multiplex assays were efficient (reaction efficiencies $=95-109 \%$ ), sensitive (covering a $>10.0 \mathrm{Ct}$ range up to $\mathrm{Ct}=33.0$ with $\mathrm{R}^{2}$ values $>0.99)$, specific (TaqMan chemistry), and reproducible $(\mathrm{CV}=4.5-12.1 \%)$. 
Table 3. Overview of the true positive (TP), false negative (FN), true negative (TN), and false positive (FP) rates for each assay and for each mosquito pool, as well as in total for the Vector Study. The five different colors (Pool \#1 ... \#5) refer to the five different pools of mosquitoes (Figure 1). The numbering in the first column indicates the VectorDisk reaction chamber where an assay is expected positive or negative. The grey horizontal shading in some assay rows (accompanied by the symbol ' - ') means that neither positive nor negative signal was expected, because the primer/probe mixtures stored in these chambers were expected to give signals in other detection channels.

\begin{tabular}{|c|c|c|c|c|c|c|c|c|c|c|c|c|c|c|c|c|c|c|c|c|c|c|c|c|c|}
\hline \multirow{2}{*}{\multicolumn{2}{|c|}{$\begin{array}{c}\text { No. of Lysate Pool } \\
\text { Green detection channel }\end{array}$}} & \multicolumn{4}{|c|}{ Pool \#1 } & \multicolumn{4}{|c|}{ Pool \#2 } & \multicolumn{4}{|c|}{ Pool \#3 } & \multicolumn{4}{|c|}{ Pool \#4 } & \multicolumn{4}{|c|}{ Pool \#5 } & \multicolumn{4}{|c|}{ Overall } \\
\hline & & TP & FN & $\mathrm{TN}$ & FP & TP & FN & TN & FP & TP & FN & TN & FP & TP & FN & TN & FP & TP & FN & $\mathrm{TN}$ & FP & TP & FN & TN & FP \\
\hline 2 & Species ID (Aq) & & & $4 / 4$ & $0 / 4$ & & & $4 / 4$ & $0 / 4$ & & & $4 / 4$ & $0 / 4$ & & & $3 / 3$ & $0 / 3$ & & & $3 / 3$ & $0 / 3$ & & & $18 / 18$ & $0 / 18$ \\
\hline 3 & Molecular Forms (S) & $4 / 4$ & $0 / 4$ & & & $4 / 4$ & $0 / 4$ & & & $4 / 4$ & $0 / 4$ & & & $3 / 3$ & $0 / 3$ & & & $3 / 3$ & $0 / 3$ & & & $18 / 18$ & $0 / 18$ & & \\
\hline 4 & $\mathrm{Kdr}(\mathrm{Rw})$ & & & $4 / 4$ & $0 / 4$ & & & $4 / 4$ & $0 / 4$ & & & $4 / 4$ & $0 / 4$ & & & $3 / 3$ & $0 / 3$ & & & $3 / 3$ & $0 / 3$ & & & $18 / 18$ & $0 / 18$ \\
\hline 5 & $\mathrm{Kdr}+(\mathrm{R})$ & & & $4 / 4$ & $0 / 4$ & & & $4 / 4$ & $0 / 4$ & & & $4 / 4$ & $0 / 4$ & & & $3 / 3$ & $0 / 3$ & & & $3 / 3$ & $0 / 3$ & & & $18 / 18$ & $0 / 18$ \\
\hline 6 & iAChe (R) & & & $4 / 4$ & $0 / 4$ & & & $4 / 4$ & $0 / 4$ & & & $4 / 4$ & $0 / 4$ & & & $3 / 3$ & $0 / 3$ & & & $3 / 3$ & $0 / 3$ & & & $18 / 18$ & $0 / 18$ \\
\hline 7 & P. falciparum & & & $4 / 4$ & $0 / 4$ & & & $4 / 4$ & $0 / 4$ & & & $4 / 4$ & $0 / 4$ & & & $3 / 3$ & $0 / 3$ & & & $3 / 3$ & $0 / 3$ & & & $18 / 18$ & $0 / 18$ \\
\hline 8 & - & & & & & & & & & & & & & & & & & & & & & & & & \\
\hline 9 & Detox (A) RPS7 & $3 / 4$ & $1 / 4$ & & & $4 / 4$ & $0 / 4$ & & & $4 / 4$ & $0 / 4$ & & & $3 / 3$ & $0 / 3$ & & & $3 / 3$ & $0 / 3$ & & & $17 / 18$ & $1 / 18$ & & \\
\hline 10 & Detox (B) RPS7 & $4 / 4$ & $0 / 4$ & & & $4 / 4$ & $0 / 4$ & & & $4 / 4$ & $0 / 4$ & & & $2 / 3$ & $1 / 3$ & & & $3 / 3$ & $0 / 3$ & & & $17 / 18$ & $1 / 18$ & & \\
\hline 11 & Detox (C) RPS7 & $4 / 4$ & $0 / 4$ & & & $3 / 4$ & $1 / 4$ & & & $4 / 4$ & $0 / 4$ & & & $2 / 3$ & $1 / 3$ & & & $3 / 3$ & $0 / 3$ & & & $16 / 18$ & $2 / 18$ & & \\
\hline 12 & Detox (D) RPS7 & $4 / 4$ & $0 / 4$ & & & $4 / 4$ & $0 / 4$ & & & $3 / 4$ & $1 / 4$ & & & $3 / 3$ & $0 / 3$ & & & $3 / 3$ & $0 / 3$ & & & $17 / 18$ & $1 / 18$ & & \\
\hline \multicolumn{2}{|c|}{ Yellow detection channel } & TP & FN & $\mathrm{TN}$ & FP & TP & FN & $\mathrm{TN}$ & FP & TP & FN & TN & FP & TP & FN & TN & FP & TP & FN & $\mathrm{TN}$ & FP & TP & FN & TN & FP \\
\hline 2 & Species ID (Ag) & $4 / 4$ & $0 / 4$ & & & $4 / 4$ & $0 / 4$ & & & $4 / 4$ & $0 / 4$ & & & $3 / 3$ & $0 / 3$ & & & $3 / 3$ & $0 / 3$ & & & $18 / 18$ & $0 / 18$ & & \\
\hline 3 & $\begin{array}{l}\text { Molecular Forms } \\
\text { (M) }\end{array}$ & & & $4 / 4$ & $0 / 4$ & & & $4 / 4$ & $0 / 4$ & & & $4 / 4$ & $0 / 4$ & & & $3 / 3$ & $0 / 3$ & & & $3 / 3$ & $0 / 3$ & & & $18 / 18$ & $0 / 18$ \\
\hline 4 & $k d r(S-w t)$ & $4 / 4$ & $0 / 4$ & & & $4 / 4$ & $0 / 4$ & & & $4 / 4$ & $0 / 4$ & & & $3 / 3$ & $0 / 3$ & & & $3 / 3$ & $0 / 3$ & & & $18 / 18$ & $0 / 18$ & & \\
\hline 5 & $k d r+(S-w t)$ & $4 / 4$ & $0 / 4$ & & & $4 / 4$ & $0 / 4$ & & & $4 / 4$ & $0 / 4$ & & & $3 / 3$ & $0 / 3$ & & & $3 / 3$ & $0 / 3$ & & & $18 / 18$ & $0 / 18$ & & \\
\hline 6 & iAChE (S-wt) & $4 / 4$ & $0 / 4$ & & & $4 / 4$ & $0 / 4$ & & & $4 / 4$ & $0 / 4$ & & & $3 / 3$ & $0 / 3$ & & & $3 / 3$ & $0 / 3$ & & & $18 / 18$ & $0 / 18$ & & \\
\hline 7 & Plasmodium oum & & & $4 / 4$ & $0 / 4$ & & & $4 / 4$ & $0 / 4$ & & & $4 / 4$ & $0 / 4$ & & & $3 / 3$ & $0 / 3$ & & & $3 / 3$ & $0 / 3$ & & & $18 / 18$ & $0 / 18$ \\
\hline 8 & $\begin{array}{l}\text { Infective stage } \\
\text { (PLP1) }\end{array}$ & & & $4 / 4$ & $0 / 4$ & & & $4 / 4$ & $0 / 4$ & & & $4 / 4$ & $0 / 4$ & & & $3 / 3$ & $0 / 3$ & & & $3 / 3$ & $0 / 3$ & & & $18 / 18$ & $0 / 18$ \\
\hline 9 & Detox (A) CYP6P3 & $3 / 4$ & $1 / 4$ & & & $4 / 4$ & $0 / 4$ & & & $3 / 4$ & $1 / 4$ & & & $3 / 3$ & $0 / 3$ & & & $3 / 3$ & $0 / 3$ & & & $16 / 18$ & $2 / 18$ & & \\
\hline 10 & Detox (B) CYP9K1 & $1 / 4$ & $3 / 4$ & & & $2 / 4$ & $2 / 4$ & & & $2 / 4$ & $2 / 4$ & & & $2 / 3$ & $1 / 3$ & & & $1 / 3$ & $2 / 3$ & & & $8 / 18$ & $10 / 18$ & & \\
\hline 11 & Detox (C) CYP6Z1 & $4 / 4$ & $0 / 4$ & & & $2 / 4$ & $2 / 4$ & & & $3 / 4$ & $1 / 4$ & & & $1 / 3$ & $2 / 3$ & & & $3 / 3$ & $0 / 3$ & & & $13 / 18$ & $5 / 18$ & & \\
\hline 12 & Detox (D) CYP6P1 & $3 / 4$ & $1 / 4$ & & & $1 / 4$ & $3 / 4$ & & & $3 / 4$ & $1 / 4$ & & & $3 / 3$ & $0 / 3$ & & & $1 / 3$ & $2 / 3$ & & & $11 / 18$ & $7 / 18$ & & \\
\hline \multicolumn{2}{|c|}{ Red detection channel } & TP & FN & TN & FP & TP & FN & $\mathrm{TN}$ & FP & TP & FN & TN & FP & TP & FN & TN & FP & TP & FN & $\mathrm{TN}$ & FP & TP & FN & $\mathrm{TN}$ & FP \\
\hline 2 & Species ID (Aa) & & & $4 / 4$ & $0 / 4$ & & & $4 / 4$ & $0 / 4$ & & & $4 / 4$ & $0 / 4$ & & & $3 / 3$ & $0 / 3$ & & & $3 / 3$ & $0 / 3$ & & & $18 / 18$ & $0 / 18$ \\
\hline 3 & - & & & & & & & & & & & & & & & & & & & & & & & & \\
\hline 4 & $\mathrm{Kdr}(\mathrm{Re})$ & & & $4 / 4$ & $0 / 4$ & & & $4 / 4$ & $0 / 4$ & & & $4 / 4$ & $0 / 4$ & & & $3 / 3$ & $0 / 3$ & & & $3 / 3$ & $0 / 3$ & & & $18 / 18$ & $0 / 18$ \\
\hline 5 & - & & & & & & & & & & & & & & & & & & & & & & & & \\
\hline 6 & - & & & & & & & & & & & & & & & & & & & & & & & & \\
\hline 7 & - & & & & & & & & & & & & & & & & & & & & & & & & \\
\hline 8 & - & & & & & & & & & & & & & & & & & & & & & & & & \\
\hline 9 & Detox (A) CYP6M2 & $1 / 4$ & $3 / 4$ & & & $4 / 4$ & $0 / 4$ & & & $2 / 4$ & $2 / 4$ & & & $0 / 3$ & $3 / 3$ & & & $3 / 3$ & $0 / 3$ & & & $10 / 18$ & $8 / 18$ & & \\
\hline 10 & Detox (B) CYP6P4 & $0 / 4$ & $4 / 4$ & & & $0 / 4$ & $4 / 4$ & & & $1 / 4$ & $3 / 4$ & & & $0 / 3$ & $3 / 3$ & & & $1 / 3$ & $2 / 3$ & & & $2 / 18$ & $16 / 18$ & & \\
\hline 11 & Detox (C) GSTE2 & $4 / 4$ & $0 / 4$ & & & $2 / 4$ & $2 / 4$ & & & $3 / 4$ & $1 / 4$ & & & $0 / 3$ & $3 / 3$ & & & $2 / 3$ & $1 / 3$ & & & $11 / 18$ & $7 / 18$ & & \\
\hline 12 & Detox (D) CYP4G16 & $3 / 4$ & $1 / 4$ & & & $2 / 4$ & $2 / 4$ & & & $3 / 4$ & $1 / 4$ & & & $3 / 3$ & $0 / 3$ & & & $0 / 3$ & $3 / 3$ & & & $11 / 18$ & $7 / 18$ & & \\
\hline
\end{tabular}


Contrary to the DNA assays, FN results were found among the RNA assays and, mostly, in the red channel. In particular, some of the Detox assays (e.g., Detox (B) K1 in yellow channel, Detox (A) CYP6M2 and Detox (B) CYP6P4 in red channel) exhibited a higher number of FN. The higher FN rate of the RNA assays may be attributed to the fact that RNA amplification includes one additional step-the RNA reverse transcription-which is more prone to inhibitors than the DNA amplification [48]. One more factor that may account for this higher FN rate in the case of RNA assays could possibly be the adsorption of reverse transcriptase to the disk surface. Given the fact that this enzyme is integrated into the lyophilized pellet that is stored in chamber C (Figure 3), undergoes rehydration and mixing, and the resultant liquid is then distributed to the reaction chambers (E), this appears to be an explanation. The above options are recorded as candidate investigation/optimization steps for the integration of the RNA-based insecticide resistance assays.

For an assessment of the intra-pool reproducibility of the results, we conducted a basic statistical analysis for each pool individually, which is summarized in Supplementary Table S4. Furthermore, and in order to have an indication of the inter-pool variation, we performed a weighted averaging (grey-colored 'Overall' columns of Supplementary Table S4), because for each specific assay we did not have the same number of data points (due to some FN cases). In an inter-pool comparison, the calculated $\mathrm{CV}$ of each assay was below $8 \%$ (the CV of the DNA assays ranging from $1.8 \%$ to $4.1 \%$, while the $\mathrm{CV}$ of the RNA assays ranging from $3.2 \%$ to $7.9 \%$ ). The CVs of individual assays in five intra-pool comparisons were also of this range. The main factors that may drive the inter-pool variation are the manual steps in disk preparation (pipetting of primers/probes, drying in the oven), and the manual preparation of mosquito samples, including the crude lysis. Therefore, the low variability-even between pools - can be attributed to the automated aliquoting into preloaded reaction cavities and is a strong indicator of the robust and reproducible performance of the VectorDisk. Regarding the intra-disk microfluidic reproducibility (i.e., among the reaction chambers), one could also make an assessment from the very comparable Ct values of the assay RPS7, targeting a house-keeping gene, which acts as normalizer, and which is detected in four chambers $(9,10,11$, and 12) in the green detection channel (Supplementary Table S4).

Overall, the Vector Study demonstrated the compatibility of the LabDisk platform with the crude lysis-direct amplification process. Results are in line with past work on assay development by the co-authors Mavridis et al. [34], who have shown that the crude lysis-direct amplification option performed very closely to a typical magnetic bead-based bind-wash-elute extraction and purification followed by PCR (comparison performed by means of the resulting Ct values). Furthermore, previous work on microfluidic integration by the authors has demonstrated the possibility of homogenizing biological matrices (e.g., human saliva [49], bacteria [50], cells [51], swabs [52]) using disk-integrated magnets that are actuated by external (still on LabDisk Player) magnets [53]. Therefore, upon suitable adaptation of the VectorDisk microfluidic design, the lysis and homogenization of mosquito pools could be translated from an ex situ manual (currently) process to an in situ automated (on disk) process, and be followed by in situ dilution and amplification towards a truly fully-automated vector-to-result analysis. This could offer an even higher degree of automation, and result in less overall analysis time, costs, and potential errors than performing manual mosquito processing and multiple PCR assays.

\subsection{The Nucleic Acid Study Results}

In the NA Study, the authors aimed to explore the applicability of the VectorDisk in the field of arboviral vectors in terms of the performance and reproducibility of the corresponding assays integrated in the disk. As no arboviral vectors were available, the experiments were done using nucleic acids (WNV-Lineage 1 and ZIKV). Furthermore, given that the mosquitoes used in the Vector Study were laboratory-reared and did not contain any malaria parasites, purified DNA and RNA from infected mosquitoes were used in the NA Study (sample 'PF-INF'). The purification process is described in previous work [29]. Nine disks were used, and the arrangement of the assays (primers/probes per reaction chamber) is shown in Table 2. From the results, we extracted true/false positivity/negativity 
rates, for each assay and in total, which are shown in Table 4. Each disk with a viral target was expected to give TP signals from two chambers where the corresponding primers and probes were pre-stored, and TN signals from all other eight chambers. Each disk with the sample mixture 'PF-INF' was expected to give TP signals from four chambers (\#5 and 10 for DNA, and \#6 and 11 for RNA detection), and TN signals from all other six chambers. This was indeed the case, and no FPs were observed, which indicates an excellent performance of specificity of the disk-integrated arboviral assays. Some representative real-time PCR curves are shown in Figure 6.

Table 4. Overview of the true positive (TP), false negative (FN), true negative (TN), and false positive (FP) rates for each assay and for each sample, as well as in total for the NA study. The numbering in the first column indicates the VectorDisk reaction chamber where an assay is expected positive or negative. The grey horizontal shading in some assay rows (accompanied by the symbol '-') means that neither positive nor negative signal was expected, because the primer/probe mixtures stored in these chambers were expected to give signals in other detection channels. The coloring of the columns 'WNV-Lineage $1^{\prime}$, 'ZIKV', and 'PF-INF' corresponds to the coloring of Figure 2. 'PF-INF' represents the mixture of P. falciparum DNA + P. falciparum infective stage RNA.

\begin{tabular}{|c|c|c|c|c|c|c|c|c|c|c|c|c|c|c|c|c|c|}
\hline \multirow{2}{*}{\multicolumn{2}{|c|}{$\begin{array}{c}\text { Sample } \\
\text { Green detection channel }\end{array}$}} & \multicolumn{4}{|c|}{ WNV-Lineage 1} & \multicolumn{4}{|c|}{ ZIKV } & \multicolumn{4}{|c|}{ PF-INF } & \multicolumn{4}{|c|}{ Overall } \\
\hline & & TP & FN & TN & FP & TP & FN & TN & FP & TP & FN & TN & FP & TP & FN & TN & FP \\
\hline 3 & - & & & & & & & & & & & & & & & & \\
\hline 5 & Plasmodium falciparum & & & $3 / 3$ & $0 / 3$ & & & $3 / 3$ & $0 / 3$ & $3 / 3$ & $0 / 3$ & & & $3 / 3$ & $0 / 3$ & $6 / 6$ & $0 / 6$ \\
\hline 6 & - & & & & & & & & & & & & & & & & \\
\hline 7 & WNV-Lineage 1 & $3 / 3$ & $0 / 3$ & & & & & $3 / 3$ & $0 / 3$ & & & $3 / 3$ & $0 / 3$ & $3 / 3$ & $0 / 3$ & $6 / 6$ & $0 / 6$ \\
\hline 10 & Plasmodium falciparum & & & $3 / 3$ & $0 / 3$ & & & $3 / 3$ & $0 / 3$ & $3 / 3$ & $0 / 3$ & & & $3 / 3$ & $0 / 3$ & $6 / 6$ & $0 / 6$ \\
\hline 11 & - & & & & & & & & & & & & & & & & \\
\hline & ow detection channel & TP & FN & TN & FP & TP & FN & TN & FP & TP & FN & TN & FP & TP & FN & TN & FP \\
\hline 2 & WNV-Lineage 2 & & & $3 / 3$ & $0 / 3$ & & & $3 / 3$ & $0 / 3$ & & & $3 / 3$ & $0 / 3$ & & & 9/9 & $0 / 9$ \\
\hline 3 & - & & & & & & & & & & & & & & & & \\
\hline $\begin{array}{l}8 \\
9\end{array}$ & - & & & & & & & & & & & & & & & & \\
\hline $\begin{array}{c}9 \\
10\end{array}$ & $\stackrel{-}{{ }^{-}}{ }^{1}$ & & & $3 / 3$ & $0 / 3$ & & & $3 / 3$ & $0 / 3$ & & & $3 / 3$ & $0 / 3$ & & & $9 / 9$ & $0 / 9$ \\
\hline $\begin{array}{l}10 \\
11\end{array}$ & $\begin{array}{c}\text { Plasmodium ovm } \\
-\end{array}$ & & & & & & & & & & & & & & & & $0 / 3$ \\
\hline & d detection channel & TP & FN & TN & FP & TP & FN & TN & FP & TP & FN & TN & FP & TP & FN & TN & FP \\
\hline 2 & - & & & & & & & & & & & & & & & & \\
\hline 3 & ZIKV & & & $3 / 3$ & $0 / 3$ & $3 / 3$ & $0 / 3$ & & & & & $3 / 3$ & $0 / 3$ & $3 / 3$ & $0 / 3$ & $6 / 6$ & $0 / 6$ \\
\hline 4 & - & & & & & & & & & & & & & & & & \\
\hline 5 & - & & & & & & & & & & & & & & & & \\
\hline 6 & Pf infective stage & & & $3 / 3$ & $0 / 3$ & & & $3 / 3$ & $0 / 3$ & $3 / 3$ & $0 / 3$ & & & $3 / 3$ & $0 / 3$ & $6 / 6$ & $0 / 6$ \\
\hline 7 & - & & & & & & & & & & & & & & & & \\
\hline 8 & ZIKV & & & $3 / 3$ & $0 / 3$ & $3 / 3$ & $0 / 3$ & & & & & $3 / 3$ & $0 / 3$ & $3 / 3$ & $0 / 3$ & $6 / 6$ & $0 / 6$ \\
\hline
\end{tabular}

The disks also included primer/probes for detection of dengue virus (DENV T1-4), WNV-Lineage 2, and P. ovale/vivax/malariae (Table 2), but since the corresponding targets were not present in any of the samples, only TN or FP could be expected from these assays. Therefore, these primers/probes were used for cross-specificity purposes (tested against the other samples) and notably, only TN results were extracted. Furthermore, after analyzing the data for a reproducibility assessment, it is noteworthy that all assays in the VectorDisk performed with an inter-disk CV $<6 \%$ (Supplementary Table S5). 


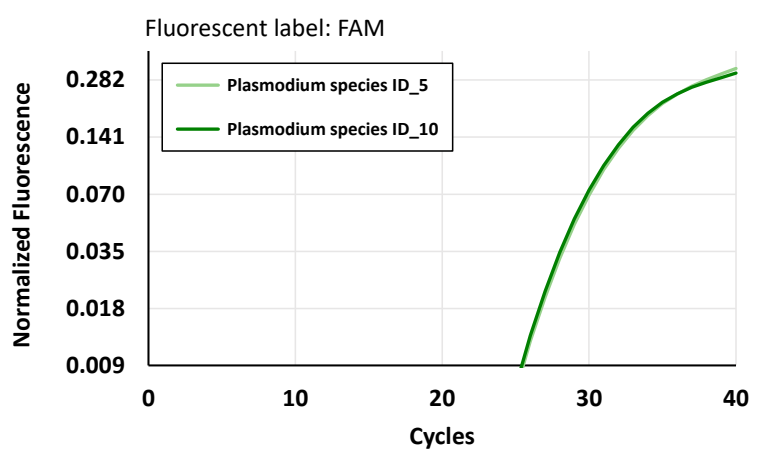

(a)

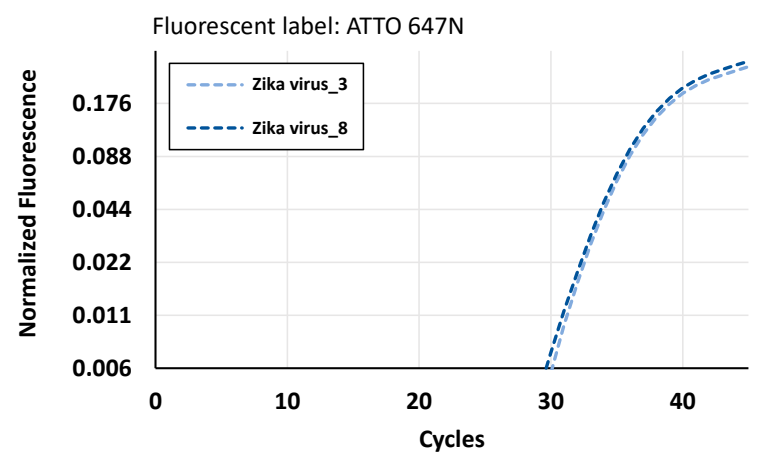

(c)

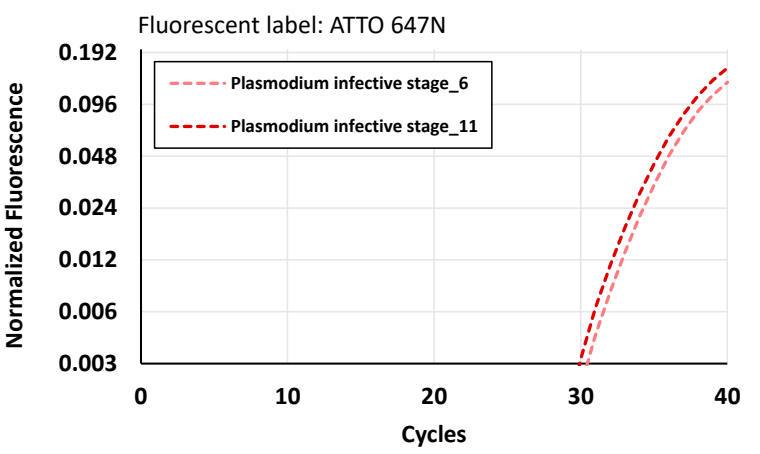

(b)

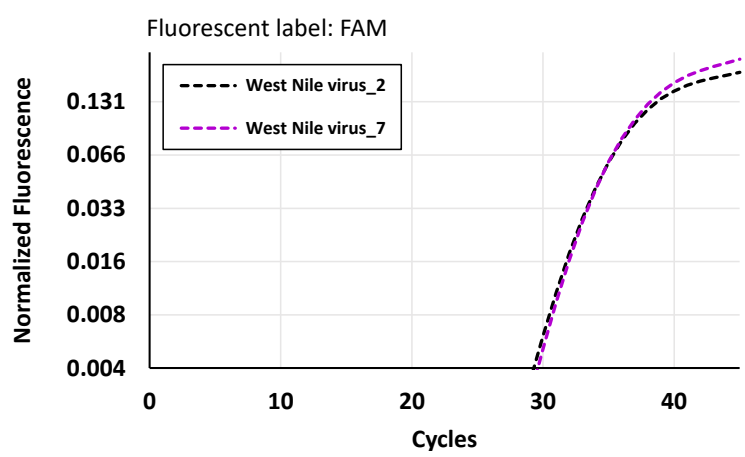

(d)

Figure 6. Representative LabDisk real-time PCR, acquired from the analysis of purified RNA for the various targets of the NA Study. (a) Pf species ID (DNA); (b) Pf infective stage (RNA); (c) ZIKV (RNA); (d) WNV-Lineage 1 (RNA). Each VectorDisk graph has two curves because each assay was included in two reaction chambers per disk (indicated in the figure legends).

Overall, the NA Study was performed by using the same disk design and fluidic operations, as well as the same lyopellet as the Vector Study, by only exchanging the primer/probes in the reaction chambers, and by slightly modifying the PCR protocol. This easy adaptability to the needs of the analysis is of utmost importance for an automated system, as it allows for a higher volume of manufacturing, resulting in lower costs (several different requests can be served by the same disk design). Furthermore, such a configuration allows a fast response to urgent needs-for instance, in the case of epidemics-because the primers/probes are de-coupled from the amplification reagents. Also important is the fact that the reagents have been developed and integrated in a way that they require no cold chain for transport, which is essential when the target settings are tropical regions. A comprehensive review of candidate analytical methods and platforms has been published by Vontas et al. [16]. The fact that the LabDisk platform has been shown to successfully detect tropical infections on human samples (malaria, dengue, chikungunya) $[26,54,55]$, in combination with the current demonstration of compatibility with analysis of multiple vector-related assays, paves the way for a One Health approach of combined human/vector diagnostics [22].

\section{Conclusions}

This work included two proof-of-principle studies. The Vector Study demonstrated the capacity of the VectorDisk to simultaneously and semi-quantitatively detect DNA- and RNA-specific targets in multiplex assays from mosquito pool samples, which were crudely lysed, diluted, and then directly amplified in the disk. A combination of multiple microfluidic reaction chambers and detection wavelengths (geometric and color multiplexing) was successfully used for this scope. The NA Study, starting from purified nucleic acids, demonstrated the rapid adaptability of the platform by changing only the primer/probe panel and the capacity to detect arboviral vector and malaria-infected vector assays. In both studies, key targets relevant to species identification, infective stage, and insecticide 
resistance markers, were detected. Both studies indicated a high reproducibility in detection of the assays, with intra-and inter-pool CVs of the PCR Ct values being $<10 \%$. High specificity was also achieved with no FPs detected in either of the Vector or NA Studies.

Overall, the outcomes of our work give a promising perspective on the platform to be applied in fully automated vector diagnostics-a platform which, once tested and validated with field-collected disease vectors, will contribute molecular entomological data that is highly relevant to decision-making in vector control programs. Regarding this implementation, we foresee two further steps: (i) the in situ (on-disk) lysis and homogenization of mosquitoes that will enable fully integrated sample preparation, which can be advantageous for minimizing hands-on work; and (ii) the transition from semi-quantitative to quantitative analysis, which will offer more detailed information related to insecticide resistances, contributing to vector surveillance and control.

Supplementary Materials: The following are available online at http:/www.mdpi.com/2227-9717/8/12/1677/s1, Table S1: Primers/probes sequences for the assays in the Vector Study, Table S2: Primers/probes sequences for the assays in the NA Study, Table S3: Microfluidic protocol to operate the VectorDisk, Table S4: Statistical analysis of the Ct values derived from five pools of mosquitoes tested with the VectorDisk during the Vector Study, Table S5: Statistical analysis of the Ct values derived from the VectorDisk results from the NA Study.

Author Contributions: Conceptualization, S.H., D.B., M.S., N.W., P.M., K.M. (Konstantinos Mavridis), J.V. and K.M. (Konstantinos Mitsakakis); methodology, S.H., D.B., M.S., B.J., M.R. and K.M. (Konstantinos Mitsakakis); software, E.M.A. and M.R.; validation, S.H., D.B., M.S. and E.M.A.; formal analysis, D.B.; investigation, S.H., D.B., M.S., J.L., E.M.A. and L.S.; resources, N.W., P.M., K.M. (Konstantinos Mavridis) and J.V.; data curation, S.H. and D.B.; writing-original draft preparation, D.B. and K.M. (Konstantinos Mitsakakis); writing—review and editing, S.H., D.B., B.J., F.v.S., N.W., P.M., K.M. (Konstantinos Mavridis) and K.M. (Konstantinos Mitsakakis); visualization, S.H., D.B. and K.M. (Konstantinos Mitsakakis); supervision, S.H., M.R., N.P., R.Z. and K.M. (Konstantinos Mitsakakis); project administration, S.H., P.M., K.M. (Konstantinos Mavridis), J.V. and K.M. (Konstantinos Mitsakakis); funding acquisition, P.M., J.V. and K.M. (Konstantinos Mitsakakis) All authors have read and agreed to the published version of the manuscript.

Funding: This project has received funding from the European Union's Horizon 2020 research and innovation programme under grant agreements No 688207 ('DMC-MALVEC' project) and 731060 ('Infravec2' project). The article processing charge was funded by the Baden-Wuerttemberg Ministry of Science, Research and Art and the University of Freiburg in the funding programme Open Access Publishing.

Acknowledgments: The authors would like to acknowledge the Hahn-Schickard Lab-on-a-Chip Foundry Service for LabDisk production as well as BEI Resources for providing the viral genomic RNA samples used in this study. The insectary at the Swiss Tropical and Public Health Institute provided specimens of the Kisumu colony that originates from an MRA-762 egg batch provided by BEI Resources.

Conflicts of Interest: The authors declare no conflict of interest. The funders had no role in the design of the study; in the collection, analyses, or interpretation of data; in the writing of the manuscript, or in the decision to publish the results.

\section{References}

1. WHO. Global Vector Control Response 2017-2030; World Health Organization (WHO): Geneva, Switzerland, 2017; Available online: https://www.who.int/vector-control/publications/global-control-response/en (accessed on 18 November 2020).

2. Müller, R.; Reuss, F.; Kendrovski, V.; Montag, D. Vector-borne diseases. In Biodiversity and Health in the Face of Climate Change; Marselle, M., Stadler, J., Korn, H., Irvine, K., Bonn, A., Eds.; Springer: Cham, Switzerland, 2019; pp. 67-90. [CrossRef]

3. Vorou, R. Zika virus, vectors, reservoirs, amplifying hosts, and their potential to spread worldwide: What we know and what we should investigate urgently. Int. J. Infect. Dis. 2016, 48, 85-90. [CrossRef]

4. Heyman, P.; Cochez, C.; Hofhuis, A.; van der Giessen, J.; Sprong, H.; Porter, S.R.; Losson, B.; Saegerman, C.; Donoso-Mantke, O.; Niedrig, M.; et al. A clear and present danger: Tick-borne diseases in Europe. Expert Rev. Anti Infect. Ther. 2010, 8, 33-50. [CrossRef]

5. Rochlin, I.; Ninivaggi, D.V.; Hutchinson, M.L.; Farajollahi, A. Climate change and range expansion of the Asian Tiger Mosquito (Aedes albopictus) in northeastern USA: Implications for public health practitioners. PLoS ONE 2013, 8, e60874. [CrossRef] 
6. Medlock, J.M.; Hansford, K.M.; Schaffner, F.; Versteirt, V.; Hendrickx, G.; Zeller, H.; Van Bortel, W. A review of the invasive mosquitoes in Europe: Ecology, public health risks, and control options. Vector Borne Zoonotic Dis. 2012, 12, 435-447. [CrossRef]

7. Rezza, G.; Nicoletti, L.; Angelini, R.; Romi, R.; Finarelli, A.C.; Panning, M.; Cordioli, P.; Fortuna, C.; Boros, S.; Magurano, F.; et al. Infection with chikungunya virus in Italy: An outbreak in a temperate region. Lancet 2007, 370, 1840-1846. [CrossRef]

8. Venturi, G.; Di Luca, M.; Fortuna, C.; Remoli, M.E.; Riccardo, F.; Severini, F.; Toma, L.; Del Manso, M.; Benedetti, E.; Caporali, M.G.; et al. Detection of a chikungunya outbreak in Central Italy, August to September 2017. Eurosurveillance 2017, 22, 11-14. [CrossRef]

9. Giron, S.; Franke, F.; Decoppet, A.; Cadiou, B.; Travaglini, T.; Thirion, L.; Durand, G.; Jeannin, C.; L'Ambert, G.; Grard, G.; et al. Vector-borne transmission of Zika virus in Europe, southern France, August 2019. Eurosurveillance 2019, 24, 2-5. [CrossRef] [PubMed]

10. Kioulos, I.; Kampouraki, A.; Morou, E.; Skavdis, G.; Vontas, J. Insecticide resistance status in the major West Nile virus vector Culex pipiens from Greece. Pest Manag. Sci. 2014, 70, 623-627. [CrossRef] [PubMed]

11. Pervanidou, D.; Vakali, A.; Georgakopoulou, T.; Panagiotopoulos, T.; Patsoula, E.; Koliopoulos, G.; Politis, C.; Stamoulis, K.; Gavana, E.; Pappa, S.; et al. West Nile virus in humans, Greece, 2018: The largest seasonal number of cases, 9 years after its emergence in the country. Eurosurveillance 2020, 25, 15-27. [CrossRef]

12. Gossner, C.M.; Marrama, L.; Carson, M.; Allerberger, F.; Calistri, P.; Dilaveris, D.; Lecollinet, S.; Morgan, D.; Nowotny, N.; Paty, M.; et al. West Nile virus surveillance in Europe: Moving towards an integrated animal-human-vector approach. Eurosurveillance 2017, 22, 10-19. [CrossRef]

13. Bhatt, S.; Weiss, D.J.; Cameron, E.; Bisanzio, D.; Mappin, B.; Dalrymple, U.; Battle, K.; Moyes, C.L.; Henry, A.; Eckhoff, P.A.; et al. The effect of malaria control on Plasmodium falciparum in Africa between 2000 and 2015. Nature 2015, 526, 207-211. [CrossRef] [PubMed]

14. Ranson, H.; Lissenden, N. Insecticide resistance in African Anopheles Mosquitoes: A worsening situation that needs urgent action to maintain malaria control. Trends Parasitol. 2015, 32, 187-196. [CrossRef] [PubMed]

15. Hemingway, J.; Field, L.; Vontas, J. An overview of insecticide resistance. Science 2002, 298, 96-97. [CrossRef] [PubMed]

16. Vontas, J.; Mavridis, K. Vector population monitoring tools for insecticide resistance management: Myth or fact? Pest. Biochem. Physiol. 2019, 162, 54-60. [CrossRef] [PubMed]

17. Bass, C.; Williamson, M.S.; Field, L.M. Development of a multiplex real-time PCR assay for identification of members of the Anopheles gambiae species complex. Acta Trop. 2008, 107, 50-53. [CrossRef] [PubMed]

18. Bass, C.; Nikou, D.; Blagborough, A.M.; Vontas, J.; Sinden, R.E.; Williamson, M.S.; Field, L.M. PCR-based detection of Plasmodium in Anopheles mosquitoes: A comparison of a new high-throughput assay with existing methods. Malar. J. 2008, 7, 177. [CrossRef]

19. Bass, C.; Nikou, D.; Vontas, J.; Donnelly, M.J.; Williamson, M.S.; Field, L.M. The vector population monitoring tool (VPMT): High-throughput DNA-based diagnostics for the monitoring of mosquito vector populations. Malar. Res. Treat. 2010, 2010, 190434. [CrossRef]

20. Donnelly, M.J.; Isaacs, A.T.; Weetman, D. Identification, validation, and application of molecular diagnostics for insecticide resistance in malaria vectors. Trends Parasitol. 2016, 32, 197-206. [CrossRef]

21. Weetman, D.; Donnelly, M.J. Evolution of insecticide resistance diagnostics in malaria vectors. Trans. R. Soc. Trop. Med. Hyg. 2015, 109, 291-293. [CrossRef]

22. Mitsakakis, K.; Hin, S.; Muller, P.; Wipf, N.; Thomsen, E.; Coleman, M.; Zengerle, R.; Vontas, J.; Mavridis, K. Converging human and malaria vector diagnostics with data management towards an integrated holistic one health approach. Int. J. Environ. Res. Public Health 2018, 15, 259. [CrossRef]

23. WHO. Microscopy; World Health Organization: Geneva, Switzerland, 2017. Available online: www.who.int/ malaria/areas/diagnosis/microscopy/en (accessed on 9 August 2020).

24. Vontas, J.; Mitsakakis, K.; Zengerle, R.; Yewhalaw, D.; Sikaala, C.H.; Etang, J.; Fallani, M.; Carman, B.; Muller, P.; Chouaibou, M.; et al. Automated innovative diagnostic, data management and communication tool, for improving malaria vector control in endemic settings. Stud. Health Technol. Inform. 2016, 224, 54-60. [PubMed] 
25. Czilwik, G.; Messinger, T.; Strohmeier, O.; Wadle, S.; von Stetten, F.; Paust, N.; Roth, G.; Zengerle, R.; Saarinen, P.; Niittymaki, J.; et al. Rapid and fully automated bacterial pathogen detection on a centrifugal-microfluidic LabDisk using highly sensitive nested PCR with integrated sample preparation. Lab Chip 2015, 15, 3749-3759. [CrossRef] [PubMed]

26. Hin, S.; Lopez-Jimena, B.; Bakheit, M.; Klein, V.; Stack, S.; Fall, C.; Sall, A.; Enan, K.; Frischmann, S.; Gillies, L.; et al. The FeverDisk: Multiplex detection of fever-causing pathogens for rapid diagnosis of tropical diseases. In Proceedings of the 21st International Conference on Miniaturized Systems for Chemistry and Life Sciences, $\mu$ TAS 2017, Savannah, GA, USA, 22-26 October 2017; pp. 7-8.

27. Rombach, M.; Hin, S.; Specht, M.; Johannsen, B.; Lüddecke, J.; Paust, N.; Zengerle, R.; Roux, L.; Sutcliffe, T.; Pecham, J.R.; et al. RespiDisk: A point-of-care platform for fully automated detection of respiratory tract infection pathogens in clinical samples. Analyst 2020, 145, 7040-7047. [CrossRef] [PubMed]

28. Vernick, K.D. Infravec2: Expanding researcher access to insect vector tools and resources. Pathog. Glob. Health 2017, 111, 217-218. [CrossRef] [PubMed]

29. Kefi, M.; Mavridis, K.; Simoes, M.L.; Dimopoulos, G.; Siden-Kiamos, I.; Vontas, J. New rapid one-step PCR diagnostic assay for Plasmodium falciparum infective mosquitoes. Sci. Rep. 2018, 8, 1462. [CrossRef] [PubMed]

30. Bass, C.; Nikou, D.; Donnelly, M.J.; Williamson, M.S.; Ranson, H.; Ball, A.; Vontas, J.; Field, L.M. Detection of knockdown resistance (kdr) mutations in Anopheles gambiae: A comparison of two new high-throughput assays with existing methods. Malar. J. 2007, 6, 111. [CrossRef]

31. Mavridis, K.; Wipf, N.; Müller, P.; Traore, M.M.; Muller, G.; Vontas, J. Detection and monitoring of insecticide resistance mutations in Anopheles gambiae: Individual vs pooled specimens. Genes 2018, 9, 479. [CrossRef]

32. Jones, C.M.; Liyanapathirana, M.; Agossa, F.R.; Weetman, D.; Ranson, H.; Donnelly, M.J.; Wilding, C.S. Footprints of positive selection associated with a mutation (N1575Y) in the voltage-gated sodium channel of Anopheles gambiae. Proc. Natl. Acad. Sci. USA 2012, 109, 6614-6619. [CrossRef]

33. Bass, C.; Nikou, D.; Vontas, J.; Williamson, M.S.; Field, L.M. Development of high-throughput real-time PCR assays for the identification of insensitive acetylcholinesterase (ace-1R) in Anopheles gambiae. Pestic. Biochem. Physiol. 2010, 96, 80-85. [CrossRef]

34. Mavridis, K.; Wipf, N.; Medves, S.; Erquiaga, I.; Müller, P.; Vontas, J. Rapid multiplex gene expression assays for monitoring metabolic resistance in the major malaria vector Anopheles gambiae. Parasites Vectors 2019, 12, 9. [CrossRef]

35. Del Amo, J.; Sotelo, E.; Fernandez-Pinero, J.; Gallardo, C.; Llorente, F.; Aguero, M.; Jimenez-Clavero, M.A. A novel quantitative multiplex real-time RT-PCR for the simultaneous detection and differentiation of West Nile virus lineages 1 and 2, and of Usutu virus. J. Virol. Methods 2013, 2, 321-327. [CrossRef] [PubMed]

36. Chan, J.F.W.; Yip, C.C.Y.; Tee, K.M.; Zhu, Z.; Tsang, J.O.L.; Chik, K.K.H.; Tsang, T.G.W.; Chan, C.C.S.; Poon, V.K.M.; Sridhar, S.; et al. Improved detection of Zika virus RNA in human and animal specimens by a novel, highly sensitive and specific real-time RT-PCR assay targeting the 5'-untranslated region of Zika virus. Trop. Med. Int. Health 2017, 22, 594-603. [CrossRef] [PubMed]

37. Hahn-Schickard Lab-on-a-Chip Foundry. Available online: https://www.hahn-schickard.de/en/production/ lab-on-a-chip-foundry (accessed on 18 November 2020).

38. Focke, M.; Stumpf, F.; Faltin, B.; Reith, P.; Bamarni, D.; Wadle, S.; Müller, C.; Reinecke, H.; Schrenzel, J.; Francois, P. Microstructuring of polymer films for sensitive genotyping by real-time PCR on a centrifugal microfluidic platform. Lab Chip 2010, 10, 2519-2526. [CrossRef] [PubMed]

39. Focke, M.; Kosse, D.; Al-Bamerni, D.; Lutz, S.; Müller, C.; Reinecke, H.; Zengerle, R.; von Stetten, F. Microthermoforming of microfluidic substrates by soft lithography ( $\mu$ TSL): Optimization using design of experiments. J. Micromech. Microeng. 2011, 21, 115002. [CrossRef]

40. Simmons, M.; Myers, T.; Guevara, C.; Jungkind, D.; Williams, M.; Houng, H.S. Development and validation of a quantitative, one-step, multiplex, real-time reverse transcriptase PCR assay for detection of dengue and Chikungunya viruses. J. Clin. Microbiol. 2016, 54, 1766-1773. [CrossRef]

41. Kosse, D.; Buselmeier, D.; Müller, C.; Zengerle, Z.; von Stetten, F. Gas pressure assisted thermal bonding of film-based Lab-on-a-Chip cartridges. In Proceedings of the Mikrosystemtechnik-Kongress, Darmstadt, Germany, 10-12 October 2011; pp. 579-582. 
42. Keller, M.; Czilwik, G.; Schott, J.; Schwarz, I.; Dormanns, K.; von Stetten, F.; Zengerle, R.; Paust, N. Robust temperature change rate actuated valving and switching for highly integrated centrifugal microfluidics. Lab Chip 2017, 17, 864-875. [CrossRef]

43. Zehnle, S.; Schwemmer, F.; Roth, G.; von Stetten, F.; Zengerle, R.; Paust, N. Centrifugo-dynamic inward pumping of liquids on a centrifugal microfluidic platform. Lab Chip 2012, 12, 5142-5145. [CrossRef]

44. Hin, S.; Paust, N.; Keller, M.; Rombach, M.; Strohmeier, O.; Zengerle, R.; Mitsakakis, K. Temperature change rate actuated bubble mixing for homogeneous rehydration of dry pre-stored reagents in centrifugal microfluidics. Lab Chip 2018, 18, 362-370. [CrossRef]

45. Burger, S.; Schulz, M.; von Stetten, F.; Zengerle, R.; Paust, N. Rigorous buoyancy driven bubble mixing for centrifugal microfluidics. Lab Chip 2016, 16, 261-268. [CrossRef]

46. Mark, D.; Weber, P.; Lutz, S.; Focke, M.; Zengerle, R.; von Stetten, F. Aliquoting on the centrifugal microfluidic platform based on centrifugo-pneumatic valves. Microfluid. Nanofluid. 2011, 10, 1279-1288. [CrossRef]

47. Strohmeier, O.; Keller, M.; Schwemmer, F.; Zehnle, S.; Mark, D.; von Stetten, F.; Zengerle, R.; Paust, N. Centrifugal microfluidic platforms: Advanced unit operations and applications. Chem. Soc. Rev. 2015, 44, 6187-6229. [CrossRef] [PubMed]

48. Fleige, S.; Pfaffl, M.W. RNA integrity and the effect on the real-time qRT-PCR performance. Mol. Asp. Med. 2006, 27, 126-139. [CrossRef] [PubMed]

49. Johannsen, B.; Müller, L.; Baumgartner, D.; Karkossa, L.; Fruh, S.M.; Bostanci, N.; Karpisek, M.; Zengerle, R.; Paust, N.; Mitsakakis, K. Automated pre-analytic processing of whole saliva using magnet-beating for point-of-care protein biomarker analysis. Micromachines 2019, 10, 833. [CrossRef] [PubMed]

50. Kim, J.; Jang, S.H.; Jia, G.Y.; Zoval, J.V.; Da Silva, N.A.; Madou, M.J. Cell lysis on a microfluidic CD (compact disc). Lab Chip 2004, 4, 516-522. [CrossRef]

51. Kido, H.; Micic, M.; Smith, D.; Zoval, J.; Norton, J.; Madou, M. A novel, compact disk-like centrifugal microfluidics system for cell lysis and sample homogenization. Colloid Surf. B Biointerfaces 2007, 58, 44-51. [CrossRef]

52. Siegrist, J.; Gorkin, R.; Bastien, M.; Stewart, G.; Peytavi, R.; Kido, H.; Bergeron, M.; Madou, M. Validation of a centrifugal microfluidic sample lysis and homogenization platform for nucleic acid extraction with clinical samples. Lab Chip 2010, 10, 363-371. [CrossRef]

53. Hin, S.; Paust, N.; Rombach, M.; Lueddecke, J.; Specht, M.; Zengerle, R.; Mitsakakis, K. Minimizing ethanol carry-over in centrifugal microfluidic nucleic acid extraction by advanced bead handling and management of diffusive mass transfer. In Proceedings of the 20th International Conference on Solid-State Sensors, Actuators and Microsystems \& Eurosensors XXXIII, Berlin, Germany, 23-27 June 2019; pp. 130-133. [CrossRef]

54. Lopez-Jimena, B.; Bekaert, M.; Bakheit, M.; Frischmann, S.; Patel, P.; Simon-Loriere, E.; Lambrechts, L.; Duong, V.; Dussart, P.; Harold, G.; et al. Development and validation of four one-step real-time RT-LAMP assays for specific detection of each dengue virus serotype. PLoS Negl. Trop. Dis. 2018, 12, e0006381. [CrossRef]

55. Lopez-Jimena, B.; Wehner, S.; Harold, G.; Bakheit, M.; Frischmann, S.; Bekaert, M.; Faye, O.; Sall, A.A.; Weidmann, M. Development of a single-tube one-step RT-LAMP assay to detect the Chikungunya virus genome. PLoS Negl. Trop. Dis. 2018, 12, e0006448. [CrossRef]

Publisher's Note: MDPI stays neutral with regard to jurisdictional claims in published maps and institutional affiliations.

(C) 2020 by the authors. Licensee MDPI, Basel, Switzerland. This article is an open access article distributed under the terms and conditions of the Creative Commons Attribution (CC BY) license (http://creativecommons.org/licenses/by/4.0/). 